\title{
The analytic hierarchy process to support decision-making processes in infrastructure projects with social impact
}

\author{
Manuel Álvarez, Ana Moreno and Carlos Mataix
}

\begin{abstract}
There is an increasing awareness among all kinds of organisations (in business, government and civil society) about the benefits of jointly working with stakeholders to satisfy both their goals and the social demands placed upon them. This is particularly the case within corporate social responsibility (CSR) frameworks. In this regard, multi-criteria tools for decision-making like the analytic hierarchy process (AHP) described in the paper can be useful for the building relationships with stakeholders. Since these tools can reveal decision-maker's preferences, the integration of opinions from various stakeholders in the decision-making process may result in better and more innovative solutions with significant shared value. This paper is based on ongoing research to assess the feasibility of an AHP-based model to support CSR decisions in large infrastructure projects carried out by Red Eléctrica de España, the sole transmission agent and operator of the Spanish electricity system.
\end{abstract}

Keywords: analytic hierarchy process; decision-making; innovation; stakeholders; corporate social responsibility

\section{Stakeholder relationships and organisational innovation}

This paper makes a proposal of a specific analytic hierarchy process (AHP) model application to integrate stakeholders' opinions and preferences in infrastructures projects with a significant social impact. The AHP has been widely used to support decision processes, but there is a lack of experiences in CSR departments. Apparently, it is not a usual tool to guide the relationship with stakeholders and the decision process in which they are involved.

Through an action research process, the feasibility of the application has been tested for the large infrastructure projects developed by the Spanish company Red Eléctrica de España (REE). ${ }^{1}$

In large infrastructures with a high social impact, it is very important to consider a wide set of factors, beyond technical or economical ones. The process to choose the best alternative involves a wide set of stakeholders who often aim different objectives. In these situations, it is more and more usual for organisations to try to find a solution that satisfies as far as possible social demands, without being less satisfying for its strategic and day-byday goals.

According to Freeman (1984) stakeholders are 'any group or individual who can affect or is affected by the achievement of the firm's objectives' and may be either primary (those that have a direct impact on the firm usually engage in economic transactions) or 
secondary (those that are not directly involved with the firm and are not engaged in direct economic exchange but who are affected by the firm and indirectly may influence it). Clarkson (1995) argues further about the differences between stakeholders and he narrows Freeman's primary/secondary stakeholder definition by arguing that the former are those that the corporation needs to survive, such as investors, employees, customers, suppliers, governments and communities that provide infrastructures and markets.

For primary stakeholders, there are usually well-defined frameworks for relationships and, in the last years, information and communication technologies have been implemented as a tool to support and strengthen communication channels. Primary stakeholders, as shareholders, employees, providers or customers, have been 'traditionally' taken into account.

It is not the same for secondary stakeholders, even when many of them have been shown more 'essential' than 'secondary'. That is the reason why in this paper secondary stakeholders will be called simply 'non-traditional' stakeholders, to emphasise that they have not been traditionally involved in the firm, beyond the discussion about the importance they have or may have in it.

Nevertheless, neither companies can overlook the stakeholders' interests, nor stakeholders can ignore that the growth of their ability to act and to influence depends on knowing about (and participating in) networks which are configured around organisations.

The relationship between the company and 'non-traditional' stakeholders is closely tied to the corporate social responsibility (CSR) concept. In fact, when different CSR approaches, methodologies and standards are considered, it may emerge that strong stakeholder participation is a key success factor. In addition, a stakeholder orientation in a frame of CSR can be considered as a precondition for sustainability (Zink, 2005).

However, there are still some problems to change from a risk management policy to more advanced CSR policies in which stakeholders relationships are understood, firstly, as a source of innovation and valuable knowledge for the company and, secondly, as a rightful opportunity of influence and participation in the corporative management sphere (Mataix et al., 2008).

The strategy of finding shared solutions is closely linked to this advanced CSR concept which passes from a defensive approach, taken in front of environmental or social situations, to other that tries to understand the risks and the opportunities underlying in stakeholders relationships. This has to do with making relationship and dialogue models which enable the participation and commitment of the stakeholders in the decisions of the companies (AccountAbility \& Utopies, 2007; Rodríguez Fernández, 2007).

In addition, some analyses suggest that CSR and total quality management (TQM) share similar philosophical roots, that there is a substantial overlap between the elements of the two concepts, and that they show significant similarities, even to propose that TQM can be used as a vehicle for expediting the diffusion of CSR (Ghobadian, Gallear, \& Hopkins, 2007). In this line, some frameworks for the design and improvement of highperforming organisations have included CSR as an important element to be considered for achieving performance excellence (Foote, Gaffney, \& Evans, 2010). Other authors argue that, despite the fact that CSR can become well-integrated into the business excellence models, the instrumental view usually dominating them may suppress alternative and more value-based approaches to CSR (Pedersen \& Neergaard, 2008).

In some way, the new role of CSR in organisations is about internalising the new definition for stakeholder stated by Freeman in 1994, which establishes that stakeholders are those who participate in the human process of joint value creation. 
The importance of building relationship frameworks with 'non-traditional' stakeholders, like NGOs, Public Administration or mass media, lies in the possibility for them to become a source for innovation, as far as these relationships allow identifying relevant issues for the companies and their incorporation into the internal corporate processes and the strategy. Also, they can play an important role in the transformation of the internal corporate culture in an effective way according to the needs identified by the dialogue with them (Álvarez et al., 2009; Moreno et al., 2010).

In the particular case of social agents, they can be relevant stakeholders in large infrastructure projects while: (i) they act as receivers for the demands of some social groups, and also act as loudspeakers who try to meet the needs; (ii) their participation in structured networks enabled by CSR policies can be effective to add efforts in projects with a relevant social impact; (iii) they grant, jointly with local communities, a 'social license' to operate, that is, an approval or broad social acceptance for companies to develop their businesses and projects.

Nevertheless, a new challenge must be faced to achieve the participation of non-traditional stakeholders: to create effective and value communication channels for everyone and to connect the information to the organisation's processes. The use of the shared knowledge about relevant issues can be the key to overcome this challenge. But this kind of shared knowledge can only be achieved by a dialogue in which preferences and expectations of each participant are highlighted. In addition, the decision-making process must take into account these preferences in a clear way. The human factor, specifically professional abilities to facilitate and to lead agreements, is a fundamental basis to succeed.

However, apart from the human factor, others methodologies can be used to make easier and possible strong stakeholder relationships. For instance, some authors face the challenge to provide a measurement or index of corporate responsibility, based on a latent variable structural equations model, to indicate the extent to which a particular corporation has social responsibility and in which areas it lacks such responsibility, if any (Kanji \& Chopra, 2010). It is a fact that mathematical techniques and engineering tools are being used in this field.

For instance, the AHP is a technique widely used to make easier the decision-making processes in a multi-criteria and multi-stakeholder environment. In general terms, this technique arranges the factors that are important for the decision in a hierarchic structure descending from an overall goal to criteria, sub-criteria and alternatives in successive levels, then it values the importance of criteria and it makes possible an assessment of several alternatives according to these criteria (Saaty, 1990).

The advantage of the AHP consists of integrating qualitative aspects (apart from quantitative aspects) which are often counted out of analysis processes, but they can be relevant to some actors involved in the decision-making process. Some of these qualitative factors are the risk of the decision, the uncertainty, the equity, the participation level, etc. (Ávila, 2000).

\section{AHP applications in stakeholder relationships}

As mentioned before, the AHP splits a complex multi-factor problem into a hierarchy. It uses hierarchic structures and linear algebra to understand better the problem and to support the final decision. The AHP determines weights for each criteria and alternatives by analysing the judgmental matrices and by applying the mathematical theory of eigenvalues and eigenvectors. The AHP combines both subjective and objective judgments in an integrated framework based on ratio scales from simple pair wise comparisons. 
Using the AHP model to involve stakeholders in the decision-making process of an organisation is widely treated in scientific literature. The environmental and natural resource areas provide a lot of examples: applications to prioritise stakeholders' concerns about management of environmental risks (Accorsi, Apostolakis, \& Zio, 1999); to support multi-stakeholder decisions in water regulation policies (Mustajoki, Hamalainen, \& Marttunen, 2003); to include stakeholders' preferences into regional forest planning (Ananda \& Herath, 2003); to analyse stakeholders' opinions in fisheries (Mardle, Pascoe, \& Herrero, 2004; Nielsen \& Mathiesen, 2006); or to decide on land uses and farming (Ávila, 2000).

According to these authors, many advantages can be identified and easily extrapolated to our research: (i) The AHP is a simple and flexible method which makes it easier to understand the context of the problem and to carry out properly the decision-making process (Ávila, 2000); (ii) The AHP seems to be a useful tool to discover the core of decision problems, including differences and similarities between the stakeholders' different points of view (Nielsen \& Mathiesen, 2006); (iii) the AHP has the capacity to reveal stakeholders' preferences regarding objectives in an explicit way (Mardle et al., 2004); (iv) The AHP enables decision-makers, and other actors, to know reality in depth (Ávila, 2000); and (v) the AHP makes possible to assess the consensus rate among different stakeholders in a specific issue (Masozera, 2002).

These advantages were considered very important to our research, in the sense of (i) CSR departments usually lack tools or frameworks to better explain the context of the problem to their stakeholders; (ii) CSR departments usually lack tools or frameworks to reveal shared material issues; and (iii) CSR departments usually lack tools or frameworks to make clear and open the decision process to their stakeholders.

\section{Objectives and methodology of the action research}

The main objective of the research was to test an AHP model as a useful tool to support decision-making processes in the large infrastructures projects with a social impact carried out by the Spanish company REE.

Red Eléctrica is the sole transmission agent and operator of the Spanish electricity system. Its mission is to ensure the global functioning of the system guaranteeing at each moment the continuity and security of supply. The company promotes dialogue with its stakeholders and has the objective of integrating its projects socially and environmentally.

Regarding this objective, the company wanted to explore a tool which helps them to determine, in a structured framework, the following: (i) the social-environmental integration of their projects; (ii) the variation of the integration according to different alternatives for the project; (iii) the best alternative to maximise objectives of sustainability; and (iv) a prioritisation to decide when and where to start the projects.

According to this, four levels of application of the AHP model were considered for this research: (i) to measure the 'acceptability' of the projects; (ii) to study, jointly with stakeholders, the factors which have an influence on 'acceptability'; (iii) to assess the 'acceptability' of different alternatives for the project; (iv) and to decide how much of the stakeholder's preferences must be integrated.

These four levels were tested in a pilot project developed in partnership with the Corporate Responsibility Department of REE.

The pilot consisted of the assessment of several real cases, previously valuated by the current method of the company (constructed by a simple scoring system). They were reviewed and discussed with managers, analysing the possibilities of using the AHP in them. 


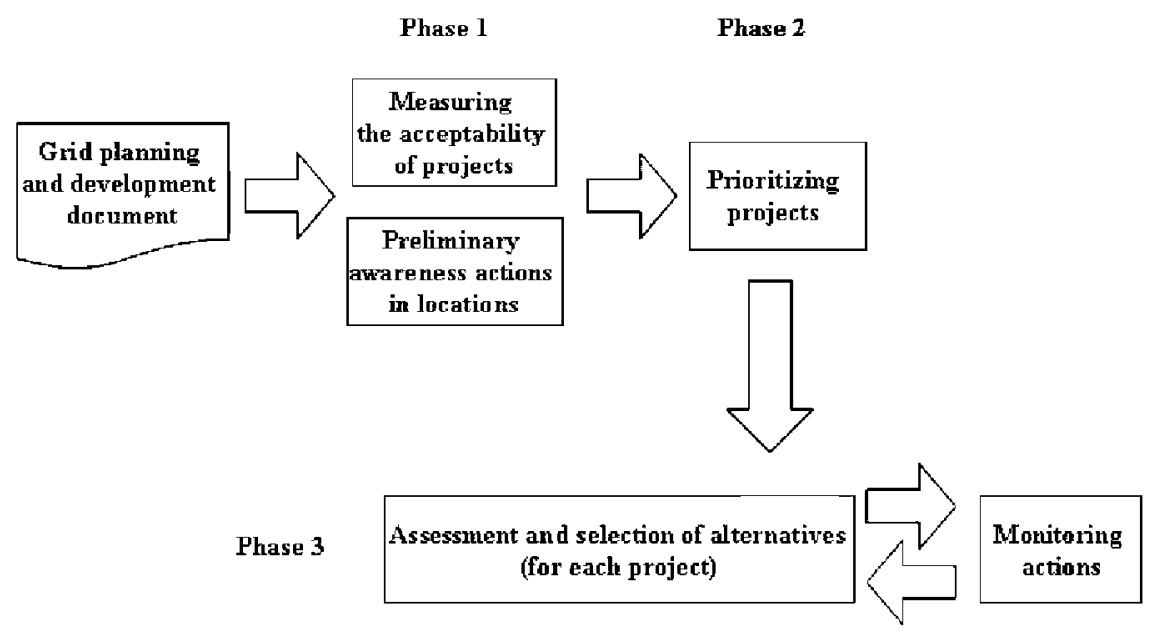

Figure 1. Simple phases involved in the integration of projects by REE.

To understand better the phases involved in the process carried out by the REE CSR department to integrate the projects in local communities, a simplification is shown in Figure 1:

So, they usually start visiting the local authorities and local NGOs in the area and, using the information collected, along with that provided by the regional REE staff, they measure the expected acceptability for the projects. Then they use this information to prioritise the projects, focusing efforts on the potentially conflictive ones. For each project, both the CSR department and the project manager, assess the alternatives to make the project more acceptable to the local community and finally follow up the actions taken. The decision problem to be solved consists of selecting the best alternative to integrate the project in the local community.

For the research, the authors selected the approach of action research. There were two main reasons to do it: the research took place in real-world situations and aimed to solve real problems. Susman (1983) distinguishes in the action research five phases to be conducted within each research cycle. Initially, a problem is identified and data are collected for a more detailed diagnosis. This is followed by a set of several possible solutions, from which a single plan of action emerges and is implemented. Data on the results of the intervention are collected and analysed, and the findings are interpreted. At this point, the problem is reassessed and the process begins another cycle. This process continues until the problem is solved. In this paper, most of the findings which are included are related to the first cycle of the action research, because the process still continues.

\section{Findings}

\section{Criteria tree and weights}

The current index used by REE is based on a set of parameters related to sustainability which are divided into four groups: (i) technical and economic $\left(K_{\mathrm{t}}\right)$; (ii) environmental $\left(K_{\mathrm{e}}\right)$; (iii) local relationships between REE and institutions $\left(K_{1}\right)$; and (iv) perceived social attitude $\left(K_{\mathrm{s}}\right)$. The parameters are valued by several managers in a simple scoring 
system with different scales for each parameter. The final value $K_{\mathrm{c}}$ of the index is calculated using the following formula:

$$
K_{\mathrm{c}}=\left(K_{\mathrm{t}}+K_{\mathrm{l}}\right)+2\left(K_{\mathrm{e}}+K_{\mathrm{s}}\right) .
$$

Regarding this, the first finding of the research is the fact that the current index is not completely capturing the genuine purpose of REE managers (i.e., to give more importance to environmental and social factors). To reach this conclusion, the research team used the AHP to reveal the weights REE was giving. As the scales of the parameters were different, the research team considered the maximum of each one to perform binary comparisons after a normalisation of the scales. So, while the current index tries to compensate the weight of environmental and social parameters giving them double weight in the final formula (resulting environmental $=0.33$, social $=0.33$, technical $=0.17$, local relationships $=0.17$, if the scales had been equal), the AHP results showed that the heterogeneous scoring system were giving in fact very different weights (environmental $=0.13$, social $=0.19$, technical $=0.54$, local relationships $=0.14$ ).

As a result, the research team proposed to use the AHP model in order to (i) calculate more accurate weights for the current criteria, or (ii) to build a new criteria tree, making possible a dialogue among different managers to valuate criteria. The main innovation for REE would be to be able to adjust measurements when the characteristics of the project suggest changing weights from current ones.

The debate with REE managers showed they considered the AHP model useful to simplify their current method, especially when they have problems to get the information needed to assess or when the project requires an ad-hoc solution. Anyway, REE should simplify the scoring system used for their current criteria.

\section{Assessment of alternatives and prioritising projects}

Starting from a defined criteria tree (partially shown in Figure 2), other proposals consisted of measuring the acceptability of a project and its alternatives.

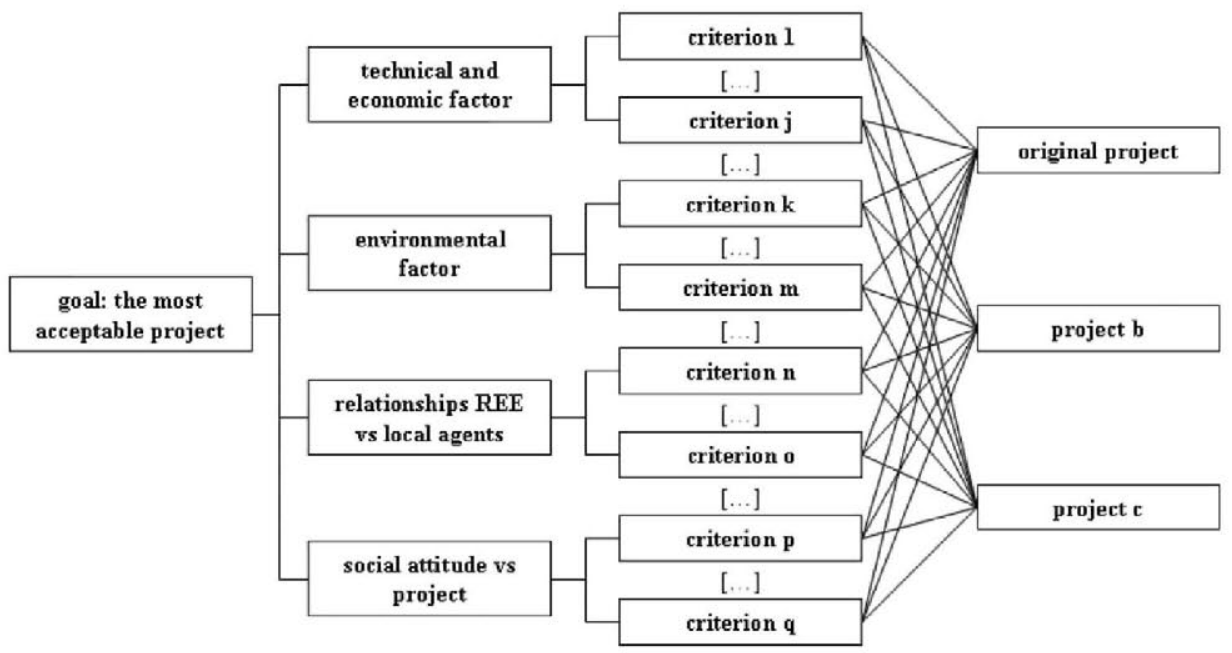

Figure 2. Hierarchical structure of the decision-making process. 
This application would allow making a sensitivity analysis to assess immediately: (i) what would happen if the weights of the criteria of the index changed; (ii) what would happen if alternatives included new characteristics which changed their scoring; (iii) what characteristics must be included in an alternative to rise its scoring.

The analysis of this application led REE to conclude that the tool is useful to structure the design of complementary actions for the projects because it shows what factors are key-factors and why (in this paper the criteria are not specified by will of REE). In addition, REE and the research group concluded the AHP model is also useful to explain, internal and externally, the final design of projects, included the most important qualitative and quantitative variables.

In addition, during the analysis, a new priority was found. It consisted of prioritising projects depending on their potential acceptability and prioritising geographical areas depending on the attention they need from the CSR department of the company.

To satisfy this demand, the research group proposed the use of Promethee II combined with the AHP, supported on the consideration of the great number of projects to be prioritised. So, the AHP would be used to calculate the weights of the criteria and Promethee II would be used to establish an order according to this criteria.

Promethee approach (see i.e. Brans, Mareschal, \& Vincke, 1984) is based on extensions of the notion of criterion. For each criterion, a specific preference function must be defined. This function is used to compute the degree of preference associated with the best action in case of pairwise comparisons. Then it calculates positive and negative preference flows for each alternative. The positive flow expresses how much an alternative is dominating the other ones, and the negative flow how much it is dominated by the other ones. In the case of Promethee II, it provides a complete ranking based on the balance of the two preference flows. The method helps the decision-maker to choose the best compromise and a clear view of the outranking relations between the alternatives is obtained.

The model was tested with a set of seven projects, randomly selected and previously scored with the REE index. Two types of test were realised: one of them using the weights from the original REE methodology $\left(w_{\mathrm{REE}}\right)$ and the other one with the weights revealed with the AHP ( $\left.w_{\mathrm{AHP}}\right)$ (Tables 1 and 2 ).

The results showed that using the intended weights from the REE index, the order of prioritising was very similar. There was a change of order between two projects (C and D) and, perhaps, the differences, in general, were clearer. On the other hand, using the weights

Table 1. Matrix for testing the model AHP-Promethee.

\begin{tabular}{lcccc}
\hline & \multicolumn{4}{c}{ Criteria (score and weights) } \\
\cline { 2 - 5 } Projects & $K_{\mathrm{t}}$ & $K_{\mathrm{e}}$ & $K_{1}$ & $K_{\mathrm{s}}$ \\
\hline Electrical line A & 1.949 & 465 & 273 & 870 \\
Electrical line B & 1290 & 465 & 0 & 920 \\
Electrical line C & 2413 & 460 & 0 & 130 \\
Electrical line D & 1900 & 395 & 212 & 150 \\
Electrical line E & 93 & 100 & 85 & 830 \\
Electrical line F & 715 & 45 & 221 & 230 \\
Electrical substation & 50 & 380 & 45 & 560 \\
$W_{\text {REE }}$ & 0.17 & 0.33 & 0.17 & 0.33 \\
$W_{\text {AHP }}$ & 0.54 & 0.13 & 0.14 & 0.19 \\
\hline
\end{tabular}


Table 2. Comparison between REE index and AHP-Promethee method to prioritise projects.

\begin{tabular}{|c|c|c|c|c|c|}
\hline \multicolumn{2}{|c|}{ Prioritising with REE index only } & \multicolumn{2}{|c|}{$\begin{array}{l}\text { Prioritising with AHP- } \\
\text { Promethee (intended } \\
\text { weights from REE index) }\end{array}$} & \multicolumn{2}{|c|}{$\begin{array}{l}\text { Prioritising with AHP- } \\
\text { Promethee (real weights } \\
\text { revealed by the AHP) }\end{array}$} \\
\hline Project & REE index value & Project & $\Phi$ & Project & $\Phi$ \\
\hline & & Electrical & 4.67 & Electric & 4.4 \\
\hline line B & 4.060 & ectrical line B & 2.83 & Electrical line $\mathrm{E}$ & 1.6 \\
\hline Electri & 3.5 & lectrical li & -0.67 & Electrical line B & 1.0 \\
\hline Electrical line D & 3.202 & Electrical line $\mathrm{C}$ & -1.17 & Electrical line D & 0.60 \\
\hline Electrical line $\mathrm{E}$ & 2.038 & Electrical line $\mathrm{E}$ & -1.33 & Electrical line $\mathrm{F}$ & -1.68 \\
\hline Electrical substation & 1.975 & Electrical substation & -2.00 & Electrical line $\mathrm{C}$ & -2.30 \\
\hline Electrical line $\mathrm{F}$ & 1.486 & Electrical line $\mathrm{F}$ & -2.33 & Electrical substation & -3.7 \\
\hline
\end{tabular}

revealed by the AHP, all the projects from the second to seventh position interchanged their place in the rank, showing better the real situation, as REE managers declared. But, above all, the new method seemed to be more flexible to analyse different alternatives when any change was introduced into the weights of the criteria. In addition, CSR REE staff considered that this new method would allow being more open and clear with stakeholders in the decision process.

\section{Stakeholder participation}

Other application which was evaluated jointly with REE was the use of the AHP to guide the stakeholder participation.

REE strongly believes that taking into account stakeholders from the beginning is the best way of developing its projects. When a new project is designed, REE tries to be in contact with councils, third sector organisations and neighbours in order to provide information and to co-design a whole project which includes additional environmental and social measures for the local community. This is a hard process because the goals and preferences of the stakeholders are heterogeneous and very often they have conflicting interests.

So, in this case, the AHP-model was evaluated in two ways: (i) to reveal stakeholders' preferences (about criteria and their weights) and to explain the determining factors of the project; and (ii) to valuate internally the weight of the stakeholders in the process.

In the first situation, the proposal consisted of building the criteria tree jointly with stakeholders, what means a participatory process with two goals: (i) to explain stakeholders the criteria and weights initially taken into account by REE; (ii) to guarantee that the criteria tree takes the various perspectives into account. The second application would imply to compare groups of stakeholders and stakeholders individually to evaluate their influences (measured as weights). It is important to highlight that the AHP in this case is just used as a tool to guide the process but not to generate 'consensus' preference vectors.

In this case, the feedback provided by REE was more prudent, as they consider this application could only be used in an ulterior phase of the project when the internal use was spread.

Anyway, REE managers and the research group agree that the AHP model should be jointly used with a complete methodology, in which the AHP would be a tool in a more complex framework. 


\section{Conclusions}

In short, the research has shown that multi-criteria techniques for decision-making processes can play an important role in cases in which the activity of the company has an important social impact and there is a will to encourage the stakeholders' participation to find a satisfying solution for all. Figure 3 shows several applications validated by REE to include in its process of integration of projects into local communities.

The REE CSR department staff has also remarked that an AHP model can be useful to develop structured relationships with stakeholders because: (i) it is a good tool for clarifying decision-making problems and for showing qualitative factors; (ii) it has a pedagogical value to explain the critical points of a project and the alternatives that can help to enhance it; (iii) it contributes to the transparency of the process as stakeholders can participate, or, to say the least, they are able to know what are the criteria used for taking a decision; (iv) internally, it can be useful for knowledge management, as it contributes to an answer in the same way to similar decisions.

However, it is clear that the AHP is a tool to help in decision-making processes, but not to take automatic decisions based on their results. In fact its main contribution, again, is to help to clarify decision problems, including qualitative factors and revealing the decision-maker and stakeholder's preferences.

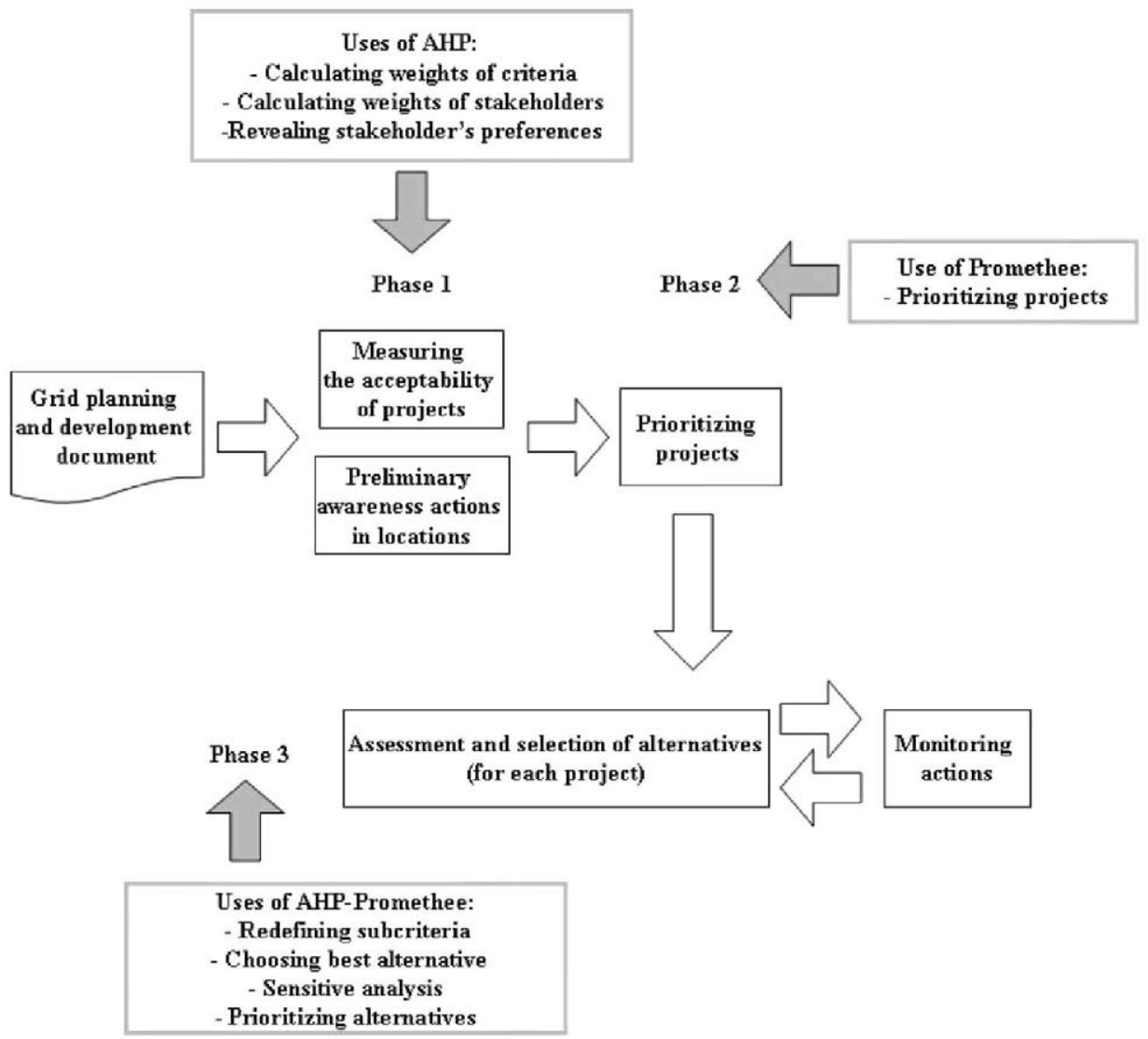

Figure 3. Applications of the AHP model and Promethee II validated with REE. 
In addition, the research has shown that the use of these tools must be integrated into larger and more complex processes in which it is necessary to develop a methodological framework to arrange stakeholder relationships. Transparency and clear information are especially important in the process, because both are considered basic elements to apply it successfully.

Moreover, it is recommended to integrate several multi-criteria techniques in a methodology so that they can better help in different tasks (prioritising, revealing preferences, etc.).

\section{Note}

1. REE is the Spanish company dedicated exclusively to the transmission of the electricity and the operation of electrical systems.

\section{References}

Accorsi, R., Apostolakis, G., \& Zio, E. (1999). Prioritizing stakeholder concerns in environmental risk management. Journal of Risk Research, 2(1), 11-29.

AccountAbility \& Utopies. (2007). Critical friends: The emerging role of stakeholder panels in corporate governance, reporting and assurance. Informe de investigación realizado por AccountAbility y Utopies.

Álvarez, M., Moreno, A., \& Mataix, C. (2009). Aplicación del modelo AHP como apoyo para la toma de decisiones en proyectos de grandes infraestructuras con impacto social. 3rd International Conference on Industrial Engineering and Industrial Management - XIII Congreso de Ingeniería de Organización (CIO 2009), Barcelona, September 2009.

Ananda, J., \& Herath, G. (2003). The use of analytic hierarchy process to incorporate stakeholder preferences into regional forest planning. Forest Policy and Economics, 5(1), 13-26.

Ávila, R. (2000, December). El AHP (proceso analítico jerárquico) y su aplicación para determinar los usos de las tierras. Informe técnico realizado para la FAO (Food and Agriculture Organization). (Proyecto GCP/RLA/126/JPN). Santiago, Chile: FAO.

Brans, J.P., Mareschal, B., \& Vincke, P. (1984). PROMETHEE: A new family of outranking methods in multicriteria analysis. In J.P. Brans (Ed.), Operational research, IFORS 84 (pp. 477-490). North Holland: Amsterdam.

Clarkson, M. (1995). A stakeholder framework for analyzing and evaluating corporate social performance. Academy of Management Review, 20(1), 92-117.

Freeman, R.E. (1984). Strategic management: A stakeholder approach. Boston, MA: Pitman.

Freeman, R.E. (1994). The politics of stakeholder approach: Some future directions. Business Ethics Quarterly, 4, 409-421.

Foote, J., Gaffney, N., \& Evans, J.R. (2010). Corporate social responsibility: Implications for performance excellence. Total Quality Management \& Business Excellence, 21(8), 799-812.

Ghobadian, A., Gallear, D., \& Hopkins, M. (2007). TQM and CSR nexus. International Journal of Quality and Reliability Management, 24(2), 704-721.

Kanji, G.P., \& Chopra, P.K. (2010). Corporate social responsibility in a global economy. Total Quality Management \& Business Excellence, 21(2), 119-143.

Mardle, S., Pascoe, S., \& Herrero, I. (2004). Management objective importance in fisheries: An evaluation using the analytic hierarchy process. Environmental Management, 33(1), 1-11.

Masozera, M.K. (2002). Socioeconomic impact analysis of the conservation of the Nyungwe forest reserve, Rwanda. Gainesville, FL: University of Florida.

Mataix, C., Moreno, A., Álvarez de Liébana, N., Álvarez, M., \& Ibisate, A.J. (2008). La estructuración de las relaciones con Grupos de Interés (stakeholders) como fuente de innovación organizativa. In en L. Saiz, Lr. Izquierdo, \& J.I. Santos (Eds.), II international conference on industrial engineering and industrial management (pp. 121-122). Burgos: University of Burgos-ADINGOR.

Moreno, A., Uriarte, L.M., \& Topa, G. (2010). La Responsabilidad Social Empresarial. Oportunidades estratégicas, organizativas y de recursos humanos. Madrid: Ed. Pirámides. 
Mustajoki, J., Hamalainen, R.P., \& Marttunen, M. (2003). Participatory multicriteria decision analysis with Web-HIPRE: A case of lake regulation policy. Environmental Modelling \& Software, 19(2004), 537-547.

Nielsen, J.R., \& Mathiesen, C. (2006). Stakeholder preferences for Danish fisheries management of sand eel and Norway pout. Fisheries Research, 77(1), 92-101.

Pedersen, E.R., \& Neergaard, P. (2008). From periphery to center: How CSR is integrated in mainstream performance management frameworks. Measuring Business Excellence, 12(1), $4-12$.

Rodríguez Fernández, J.M. (2007). Responsabilidad social corporativa y análisis económico: práctica frente a teoría. Revista Economiaz n ${ }^{\circ} 65,2^{\circ}$ cuatrimestre de 2007.

Saaty, T.L. (1990). Multicriteria decision making. The analytic hierarchy process: Planning, priority setting resource allocation. Pittsburgh, PA: RWS Publications.

Susman, G. (1983). Action research: A sociotechnical systems perspective. London: Sage Publications.

Zink, K.J. (2005). Stakeholder orientation and corporate social responsibility as a precondition for sustainability. Total Quality Management \& Business Excellence, 16(8), 1041-1052. 